\section{Sentidos da alimentação e da saúde: contribuições para a análise do Programa de Alimentação do Trabalhador}

\author{
The meaning of food and health: a contribution \\ to the analysis of the Workers' Nutrition Program
}

\author{
1 Programa de Pós-graduação \\ em Saúde Coletiva, \\ Universidade do Vale \\ do Rio dos Sinos, \\ São Leopoldo, Brasil. \\ Correspondência \\ D. Stolte \\ Programa de Pós-graduação \\ em Saúde Coletiva, \\ Universidade do Vale \\ do Rio dos Sinos. \\ Av. Unisinos 950 \\ São Leopoldo, RS \\ 93022-000, Brasil. \\ dstolte@cpovo.net
}

\begin{abstract}
This study aimed to analyze how the Workers' Nutrition Program (WNP) is being implemented in a leather shoe factory in the Vale dos Sinos region of Rio Grande do Sul State, Brazil. Qualitative and quantitative methods were used. Demographic, socioeconomic, and anthropometric data were used for descriptive purposes. Discursive data pertaining to the meaning of food and health in the context of the WNP were obtained through focus groups. It is argued that workers in this industry have considerable knowledge about the relationship between food and health. However, the WNP itself is less familiar and fails in its objective of health promotion. The article recommends that nutritionists implement educational practices in the workplace. With regard to public policy in nutrition, a more critical approach should be included in the debate, to contemplate the regionalization and decentralization of workers' health policies, allowing the inclusion of inter-sector, interdisciplinary, and multi-professional perspectives rather than focusing only on specific nutritional issues.
\end{abstract}

Nutrition Programmes and Policies; Occupational Health; Feeding
Desire Stolte 1

Élida Azevedo Hennington 1 Jefferson de Souza Bernardes 1

\section{Introdução}

Nas últimas décadas observou-se uma mudança no perfil epidemiológico da população brasileira. A denominada transição epidemiológica foi caracterizada pela diminuição da mortalidade por doenças infecciosas e aumento de óbitos causados por doenças cardiovasculares, neoplasias e causas externas, e o crescimento das doenças crônicas não-transmissíveis. A mudança do perfil de adoecimento e morte no país não ocorreu isoladamente, mas está relacionada com transformações demográficas, sócio-econômicas, culturais e ambientais 1,2,3.

Num cenário de desigualdades sociais e regionais, a conjugação de diferentes padrões de vida repercutiu no perfil nutricional da população, caracterizando também um processo de transição nutricional definida por um quadro complexo, onde há a diminuição das formas graves de desnutrição, mantendo sua cronicidade e agregando doenças chamadas da modernidade como obesidade, diabetes II e as dislipidemias 1,4. Para autores como Nascimento \& Mendes 5 , o controle dessas doenças só pode ser alcançado por meio de esforços concentrados na prevenção e controle dos fatores de risco associados, e na melhoria das condições e qualidade de vida.

No Brasil, as ações iniciais em saúde do trabalhador no que se refere, especificamente, à questão da alimentação, datam do final da dé- 
cada de 1930, quando foi instituída a obrigatoriedade de as empresas com mais de quinhentos empregados instalarem um refeitório ( $D e$ creto-Lei $n$. 1.228, de 2 de maio de 1939). Nessa mesma época foi criado o Serviço de Alimentação da Previdência Social (SAPS), que, dentre outras atribuições, tinha o objetivo de "promover a progressiva racionalização dos hábitos alimentares do trabalhador brasileiro" 6 (p. 88).

Consolidado o processo de industrialização do país, foi instituído pelo Governo Federal o Programa de Alimentação do Trabalhador (PAT), por meio da Lei n. 6.321, de 1976, regulamentada somente em 1991. O PAT é direcionado ao atendimento dos trabalhadores de baixa renda, isto é, aqueles que ganham até cinco salários mínimos mensais, visando a melhorar sua situação nutricional, promover a saúde e prevenir doenças profissionais 7. Na época de sua implantação, o PAT recomendava que as refeições maiores (almoço, jantar e ceia) deveriam ter no mínimo $1.400 \mathrm{Kcal}$, e as menores (desjejum e merenda) $300 \mathrm{Kcal}$, todas com percentual protéico-calórico no mínimo de 6\%. De acordo com o Ministério do Trabalho e Emprego (MTE), até o ano de 2003, 128.886 empresas e 9.090.739 trabalhadores foram beneficiados pelo PAT. Em 1999, por meio da comissão tripartite foi publicada a cartilha Orientação da Educação Alimentar com o objetivo de direcionar ações de educação alimentar 8 .

A partir da Portaria $n .3$ de 1o de março de 2002, da Secretaria de Inspeção do Trabalho (SIT/MTE), foi preconizado que as refeições principais devem conter $1.400 \mathrm{Kcal}$ cada uma, admitindo-se uma redução para $1.200 \mathrm{Kcal}$, no caso de atividade leve, ou acréscimo para $1.600 \mathrm{Kcal}$, no caso de atividade intensa, mediante justificativa técnica, observando-se que, para qualquer tipo de atividade, o percentual protéico-calórico deverá ser, no mínimo, de $6 \%$; o desjejum e merenda deverão conter um mínimo de $300 \mathrm{Kcal}$ e $6 \%$ de percentual protéico-calórico, cada um, e além disso, a portaria define a obrigatoriedade da realização de atividades de conscientização e educação alimentar para os trabalhadores e divulgação de métodos de vida saudável 7 .

Em decorrência das transformações no processo produtivo e perfil de saúde da população, outras demandas vêm surgindo no campo da segurança alimentar e nutricional para o atendimento das necessidades dos trabalhadores brasileiros. Recentemente, o MTE instituiu um grupo de trabalho para revisar os parâmetros nutricionais do Artigo 5o da Portaria n. 3 (Portaria n. 116, de 15 de março de 2005/ MTE) 9 .
Ainda hoje, são poucas as pesquisas sobre políticas públicas referentes à alimentação dos trabalhadores feitas no Brasil. Dentre os estudos realizados, os de Burlandy \& Anjos 10 e de Veloso \& Santana 11 e, mais recentemente, de Savio et al. 12, demonstraram que o Programa de Alimentação do Trabalhador não vem cumprindo adequadamente os seus objetivos, sendo encontrados percentuais de 38,5 a $43 \%$ de excesso de peso nas regiões Sudeste e Nordeste do país 10,12. Já Castro et al. 13, ao analisarem o padrão dietético e estado nutricional de operários de uma empresa metalúrgica do Rio de Janeiro encontraram $44,6 \%$ de sobrepeso.

A obtenção de informações sobre estado nutricional de coletividades auxilia no planejamento de ações em saúde, possibilitando o direcionamento de estratégias para atender as necessidades específicas da população em questão e não só reproduzir programas prontos e descontextualizados 13 .

É preciso aprofundar o conhecimento sobre o PAT e seus efeitos na melhoria das condições de saúde e trabalho. Torna-se relevante identificar o conhecimento dos trabalhadores a respeito do programa e compreender a forma como questões fundamentais, tais como prevenção de doenças e agravos, promoção da saúde e a relação entre alimentação e saúde são significadas por eles. O presente estudo foi desenvolvido com o objetivo de analisar as concepções dos trabalhadores em relação ao PAT em uma indústria calçadista do Sul do Brasil, por meio da análise das práticas discursivas dos trabalhadores e de parâmetros sócio-demográficos e antropométricos.

\section{O percurso metodológico}

Trata-se de um estudo qualitativo sobre as concepções dos trabalhadores em relação ao PAT numa empresa coureiro-calçadista, utilizandose o referencial de análise das práticas discursivas e produção de sentidos. Os temas abordados foram alimentação/nutrição, saúde e política pública.

O trabalho de campo foi realizado no período de janeiro de 2004 a abril de 2005, numa indústria que possui quatro unidades de produção na região do Vale do Rio dos Sinos, Rio Grande do Sul, Brasil. O estudo foi desenvolvido na unidade matriz e em uma filial próxima, totalizando, as duas unidades, 1.272 empregados, sendo 53 de setores administrativos e 1.219 trabalhadores dos setores de produção e de apoio.

Na primeira etapa da pesquisa foram reunidas informações da empresa por meio de seu 
jornal interno e realizadas entrevistas informais com o supervisor de qualidade, com o chefe do departamento pessoal e com a nutricionista, além de observação direta do modo de produção e de alimentação na empresa. A entrevista realizada com a nutricionista abordou questões relativas a operação do restaurante e sua relação com o PAT, aos cardápios, às necessidades energéticas dos trabalhadores e à adequação dos parâmetros nutricionais do programa.

Posteriormente, foi estabelecido o perfil da população de trabalhadores dos setores de produção e de apoio com base no levantamento de dados demográficos, sócio-econômicos e antropométricos e sua análise descritiva. Foram aplicados questionários durante o horário de almoço e aferidas as medidas de peso e altura. O Índice de Massa Corporal (IMC) foi calculado considerando-se o peso em quilogramas dividido pela altura ao quadrado. A classificação de IMC utilizada foi a estabelecida pela Organização Mundial da Saúde (OMS) 14, e a da circunferência abdominal de acordo com Han et al. 15, conforme níveis de intervenção segundo o gênero e OMS 14

Nesta fase, a população de estudo foi constituída pela totalidade dos trabalhadores ativos desses setores, com no mínimo seis meses de tempo de empresa e que realizaram as refeições, no mínimo, três vezes por semana no restaurante da empresa nos últimos seis meses consecutivos, anteriores ao início da pesquisa. Não foram incluídos trabalhadores com idade acima de sessenta anos e aqueles afastados por motivo de doença ou acidente no período de coleta de dados. Para a aferição de medidas antropométricas foram excluídas também as gestantes.

Concluída essa etapa, iniciou-se a fase qualitativa da pesquisa por meio da realização de grupo focal, composto por oito funcionários dos mesmos setores. Convém destacar que tanto o levantamento epidemiológico quanto o grupo focal tiveram de ser realizados durante o horário de almoço dos trabalhadores para que não houvesse prejuízo à produção.

Houve dois encontros com trabalhadores no próprio local de trabalho: no primeiro, houve a presença de sete funcionários (quatro mulheres e três homens) e no segundo, somente as mulheres compareceram. O primeiro encontro foi realizado com o objetivo de aproximar as pessoas e introduzir o assunto, preparando o mesmo para o segundo encontro onde foram discutidos os temas referentes aos objetivos da pesquisa. Para a abordagem dos temas foi elaborado previamente um roteiro que orientou a discussão. As reuniões do grupo aconteceram em uma sala nas dependências da matriz, pro- porcionando um ambiente de comodidade e tranqüilidade. A coordenação dos grupos foi realizada pela pesquisadora e acompanhada por uma auxiliar. O gravador foi ligado no início da reunião, mediante autorização dos participantes, e somente desligado após todos terem se retirado do local. A duração média de cada encontro foi de cinqüenta minutos. A seleção dos participantes do grupo ocorreu por meio de sorteio, sendo respeitados os mesmos critérios de inclusão do levantamento epidemiológico.

A caracterização do local de trabalho e da população de estudo foi feita a partir de observação direta, informações provenientes das entrevistas com funcionários, do jornal da empresa e dos resultados do levantamento sócioeconômico, demográfico e antropométrico, o que possibilitou compor um perfil geral da empresa e dos trabalhadores. Os dados quantitativos foram analisados em relação à freqüência das variáveis e os trabalhadores classificados de acordo com o IMC e circunferência da cintura.

A análise das práticas discursivas foi realizada por meio da transcrição das falas dos trabalhadores que participaram do grupo focal. $\mathrm{O}$ texto resultante serviu de base para a construção de um mapa dialógico 16,17, com o objetivo estratégico de sistematizar a análise das práticas discursivas. Ele foi utilizado para a identificação dos aspectos formais da lingüística, dos repertórios lingüísticos utilizados e da dialogia implícita na produção de sentidos 14 . O mapa foi organizado com os seguintes temas: "alimento", "alimentação", "saúde", "alimento e saúde" e "PAT". A dialogia do grupo foi disposta de forma seqüencial, na mesma ordem em que as falas surgiram, o que permitiu manter a integridade do texto e do diálogo.

Após a produção do mapa foram utilizadas duas categorias de análise: em primeiro lugar, os repertórios lingüísticos, que são as unidades analíticas básicas do discurso: vocábulos, termos, expressões, metáforas etc. Em segundo lugar, as implicaturas conversacionais 18, que são as implicações e inferências analisáveis das ações comunicativas. Essas inferências são produtoras de sentidos e buscam compreender os usos e efeitos proporcionados pelas práticas discursivas sobre a relação entre alimentação e saúde. Parte-se da concepção de que os processos comunicativos são fundamentados no princípio da cooperação, ou seja, que os falantes desejam se comunicar. Esse princípio é regido pelas chamadas máximas conversacionais. Já as implicaturas são as condições em que se argumenta a favor do rompimento ou da 
transgressão dessas máximas, que são de qualidade, quantidade, modo e pertinência. Portanto, as implicaturas são diferentes de simples especulações, pois são passíveis de serem argumentadas por meio da análise das transgressões das máximas conversacionais.

A pesquisa foi aprovada pelo Comitê de Ética em Pesquisa da Universidade do Vale do Rio dos Sinos em agosto de 2004, tendo sido respeitados todos os preceitos éticos e legais de pesquisa envolvendo seres humanos, incluindo a assinatura do Termo de Consentimento Livre e Esclarecido por todos os participantes.

\section{O local de trabalho e o modo de produção}

A indústria fabrica calçados femininos para exportação, com uma produção média total de 15.300 pares por dia. A produção é organizada em linhas, sendo que os equipamentos e mesas de trabalho ficam dispostos de forma linear e contínua. Havia 11 linhas de produção na unidade matriz e 4 linhas na Filial 10, sendo que cada uma delas produzia um tipo de calçado para um cliente específico, sendo a produção exportada principalmente para os Estados Unidos. Os funcionários trabalhavam o tempo todo de pé, em atividades parceladas, e cada linha possuía um supervisor que coordenava o trabalho e autorizava os momentos de saída da linha de produção. O turno de trabalho é de oito horas diárias, manhã e tarde.

O refeitório localiza-se em um antigo prédio da empresa, sendo classificado como de autogestão, ou seja, é administrado pela própria empresa sob a supervisão de uma nutricionista e está inscrito no PAT desde 1995. Produz cerca de 850 refeições (almoço)/dia, sendo compostas por arroz, feijão, um tipo de carne porcionada, um tipo de guarnição e uma salada, servidas em sistema de bufê. O cardápio é elaborado mensalmente pela nutricionista baseado em parâmetros do PAT e de acordo com as preferências regionais.

\section{O perfil epidemiológico dos trabalhadores}

A população de estudo foi constituída por 401 trabalhadores. Houve $33(8,15 \%)$ perdas e 4 $(0,92 \%)$ recusas, totalizando 364 trabalhadores entrevistados, sendo $53,6 \%$ homens e $46,4 \%$ mulheres.

Os trabalhadores tinham em média 28,69 anos de idade (DP $\pm 9,57$ anos) e a maioria es- tava na faixa etária de 20 a 24 anos $(27,7 \%)$. Todos os trabalhadores entrevistados freqüentavam ou já haviam freqüentado a escola, sendo que $50,3 \%$ possuíam ensino fundamental incompleto e a renda familiar per capita era de 1,6 salário mínimo. A maioria da população era constituída por trabalhadores casados ou em união estável (56,4\%).

Em relação ao perfil antropométrico, observou-se que $70,9 \%$ dos trabalhadores apresentavam sobrepeso $(62,9 \%)$ ou obesidade $(8 \%)$; em relação à circunferência abdominal, a aferição detectou que $45,5 \%$ das mulheres e $14,8 \%$ dos homens estavam acima da medida considerada normal, indicando, neste caso, risco para hipertensão arterial sistêmica, diabetes mellitus e outras doenças cardiovasculares 14,15,19.

\section{As práticas discursivas}

No primeiro encontro do grupo focal, composto por sete trabalhadores de ambos os sexos, foi explorada a relação alimento/saúde por meio da elaboração de cartazes com figuras de alimentos, para a integração do grupo e introdução do tema central. No segundo encontro, os homens não compareceram. Isto logo chamou a atenção, parecendo reforçar o fato histórico de que assuntos relacionados à alimentação são tidos como de competência e responsabilidade exclusivas das mulheres, observando-se ainda na análise que as questões de gênero acabaram perpassando o discurso das participantes durante todo o estudo.

O grupo analisado foi constituído por quatro mulheres, sendo que a média de idade era de 33,75 anos, somente uma delas era solteira e possuía o ensino fundamental completo; as demais possuíam ensino fundamental incompleto. A renda familiar per capita do grupo era de 1,5 salário mínimo.

Canesqui 20 e Woortmann 21 já apontavam que a gerência e o controle da alimentação familiar são atribuições femininas e na maior parte do mundo a preparação da comida e a produção do alimento são tarefas das mulheres 22,23. É de responsabilidade da mulher principalmente o preparo da alimentação, que é regido por regras econômicas, morais, estéticas, de higiene, uso de equipamentos e cuidados com os alimentos, situação esta que perdura até os dias de hoje, apesar da inserção cada vez maior da mulher no mercado de trabalho. Percebe-se, a partir da literatura, que o espaço da cozinha e, conseqüentemente, o preparo da refeição, o cuidado e a discussão de assuntos relacionados à alimentação de modo geral, re- 
caem sobre a mulher. Igualmente, sabe-se que o exercício profissional nesse campo (alimentação/nutrição) caracteriza-se pelo predomínio do sexo feminino. Conforme afirma Lima 24, existe uma relação estreita entre ocupação e gênero, ou seja, algumas ocupações são associadas ao gênero feminino, sendo a Nutrição um claro exemplo disto e, segundo Bosi 25, a Nutrição supera até mesmo a Enfermagem como campo de trabalho feminino. Os repertórios lingüísticos identificados com essa questão foram, por exemplo: "em casa também já faço mais do que os outros, o meu marido e a minha filha gostam”, "acompanho (o que eles - família) comem", "sábado (tem um) monte de serviço".

Historicamente, a Nutrição como profissão foi concebida para auxiliar os médicos nutrólogos; os dietistas/nutricionistas costumavam exercer funções de apoio ou chefia de serviços dietéticos 26. Viana 27, ao analisar questões que envolvem o trabalho de nutricionistas em serviços de alimentação na Bahia, associa a predominância feminina nessa prática à visão estereotipada que conjuga os "dons naturais da mulher" da esfera do privado (cozinha) à esfera do público, isto é, às Unidades de Alimentação e Nutrição (UAN). Atualmente a profissão evoluiu em relação ao espaço e abrangência das competências, mas ainda permanece predominantemente uma profissão feminina como nos mostram os dados do Conselho Federal de Nutricionistas: 93\% dos nutricionistas brasileiros são do sexo feminino 28 .

\section{Os sentidos produzidos pelas trabalhadoras}

De acordo com os objetivos desta pesquisa, sob a perspectiva de análise com base no referencial metodológico, resultaram três tópicos gerais de natureza temática: Alimentação e Saúde, Força de Trabalho, Trabalho Alienado e sua Reprodução Cotidiana e Desconhecimento/Conhecimento do PAT.

\section{Alimentação e saúde}

Os repertórios lingüísticos identificados para este tema apresentaram-se de forma sofisticada. Por exemplo: "colesterol", "triglicerídeos", "gordura, mas não excesso", "diabete já tem que cuidá com os doces”, "comer uma coisa e te fazer mal”, "comer tudo saudável”, "fazer caminhada ajuda”. Os repertórios concernentes à relação entre alimento e saúde produzem sentidos que remetem a uma perspectiva orientada pelo discurso médico. Essa sofisticação po- de ser atribuída à grande exposição na mídia de temas e situações envolvendo a relação entre alimentação e saúde. Bleil 29 e Garcia 30, considerando as mudanças nos hábitos alimentares no Brasil, afirmam que há uma maior preocupação das pessoas com a saúde, ainda que tímida, ao mesmo tempo em que ocorre um aumento da procura por alimentos de fácil preparo, que se caracterizam pela alta densidade calórica, alimentos estes massificados pela propaganda televisiva.

Em termos de implicaturas conversacionais, o rompimento com as máximas ocorreu em alguns momentos do diálogo, por exemplo, quando da referência à relação entre alimentação e saúde: "Vamos dizer assim, que nem se tu não te cuida, come de tudo, né, tem pessoas, né, a primeira coisa que, que tem problema, né, o colesterol sobe, né, o triglicerídeo, né, já afeta a diabete tudo, né, mas tem certos alimentos assim, né, que a gente precisa de tudo um pouco, né, porque senão tu deixa de comer gordura mas tem um certo, hã, hã, com é que eu vou dizer, um certo exame, né, que ele precisa de um pouco gordura também, né, daí por isso acho que tem que é come de tudo um pouco, né, nem que seja ruim ou não, mas tem que saber que nem ela colocou, né, sabe usá, né" (M. L.).

Argumenta-se aqui o rompimento com a máxima de pertinência, visto que não era esperada a preocupação medicalizada na relação entre alimento e saúde. O trecho abaixo, também fortalece tal questão, ao se afirmar que a caminhada não é somente para fins estéticos, pois as pessoas necessitam se cuidar: "Vamos dizer assim, muitas vezes, fazer caminhada, né, é pra emagrecer, daí esse aqui, mas não é só pra isso, né. A gente, o próprio organismo tem mais órgãos, né, que ele precisa de caminhada, né, não é só pra emagrecer, né" (M. L.).

Ao analisarmos o perfil antropométrico desses trabalhadores, nos defrontamos com porcentuais elevados de sobrepeso e obesidade e indicadores de risco para doenças, em contraposição a um discurso com a presença de vários repertórios que indicam um significativo conhecimento sobre o tema alimentação e saúde. Inclusive, a reprodução do discurso médico faz menção direta à prevenção de doenças e atividades de promoção da saúde. A preservação ou mudança do comportamento alimentar, segundo Garcia 31, está condicionada à recomendação médico-dietética ou ao contexto sócio-cultural e econômico.

“A comida não é apenas uma fonte de nutrição. Em todas as sociedades humanas, ela tem muitos papéis e está profundamente entrelaçada aos aspectos sociais, religiosos e econômicos 
do dia-a-dia. Para as pessoas nessas sociedades, a comida traz uma gama de significados simbólicos, que expressam e criam as relações entre os seres humanos, entre eles e os seus deuses e entre eles e o ambiente natural. O alimento, assim, é uma parte essencial do modo como a sociedade se organiza e vê o mundo que habita" 22 (p. 49).

Ou seja, a adoção de uma "dieta saudável" está intimamente relacionada à presença ou à possibilidade de uma doença. Fora deste contexto, pode estar condicionada por valores, signos e gostos atribuídos à alimentação, sujeita a circunstâncias que envolvem disponibilidade e acesso ao alimento, questões subjetivas e ao lugar que a alimentação ocupa na sociedade 23,31 .

Alguns estudos avaliam parâmetros nutricionais além dos antropométricos, tais como padrão de consumo alimentar e gasto energético 12,13.

\section{Força de trabalho, trabalho alienado e sua reprodução no cotidiano}

O modelo taylorista-fordista de produção observado na indústria; o processo de trabalho alienado; a produção em linhas, fragmentada e sem autonomia se reproduz também no comportamento e na escolha dos alimentos no refeitório da empresa, ao contrário do que preconiza Mintz 32 (p. 32) quando afirma que a alimentação é um espaço de escolha, “comer é uma atividade humana central não só por sua freqüência, constante e necessária, mas também porque cedo se torna a esfera onde se permite alguma escolha. Para cada individuo representa uma base que liga o mundo das idéias por meio de nossos atos".

A própria UAN, como uma unidade produtora e fornecedora de alimentação, não deixa de reproduzir também a lógica taylorista de trabalho, isto é, as refeições são oferecidas em linhas de distribuição, com horário fixo e prédeterminado, onde o trabalhador se serve daquilo que está disponível, permitindo somente a escolha de comer ou não comer aquilo que lhe é oferecido. Ademais, em função de o refeitório estar distante das unidades, o tempo continua fora do controle dos trabalhadores. Assim, acelera-se o ritmo de chegada ao refeitório, formando-se uma imensa fila. No seu interior, a forma de distribuição da refeição e de acomodação dos trabalhadores às mesas e a falta de conversa entre eles mantêm a lógica de linha de produção.

Os repertórios identificados reforçam ainda a associação entre refeição e força física e os critérios envolvidos na escolha dos alimentos, por exemplo: "comida reforçada”, “arroz e o fei- jão sustentam”, "quatro cinco horas alimenta”, "cada organismo necessita", "serviço forçado", "me dá fome, me dá tremedeira", "não tem escolha". Na categoria alimento e saúde, esta questão também aparece: "fico fraca começo a passá mal, é muito puxado ficá sem comê”. Vale a pena lembrar que as funções desempenhadas por homens e mulheres no setor de produção são praticamente as mesmas, demandando o mesmo esforço físico.

A Antropologia e a Sociologia têm demonstrado que os grupos culturais diferenciam-se entre si nas crenças e práticas relacionadas à comida: por exemplo, a consideração de substâncias como alimentos ou não por uma sociedade ou grupo: o papel assumido por cada um no grupo em relação ao preparo do alimento, sobre quem o serve ou a forma de servi-lo, ou ainda, em que ocasiões ocorrem as refeições e quais as pessoas que participam delas 22,23.

Woortmann 21 (p. 12) afirma que "só os alimentos fortes são comida. O principal indicador da 'fortidão' do alimento é dado pela sensação de saciedade que propicia". O alimento forte relaciona-se com a refeição oferecida pela empresa, pois esta deve propiciar, no entendimento dos trabalhadores, sustento para o corpo executar o trabalho, suportando o desgaste e o esforço físico. Classificações como forte/fraco, quente/frio são produções de sentidos e são regidas por estratégias de subsistência e por um sistema de conhecimento e de valores que norteiam a relação alimento/organismo 11,21.

Além disto, ressalta-se que durante o grupo o termo carne foi citado principalmente quando se falou na alimentação do refeitório e na categoria PAT, levando-nos também a relacionar carne como um alimento forte, que sustenta e que, em função do padrão do cardápio da empresa, é um elemento fixo e diário. Finalmente, em outra passagem, quando foram questionados sobre se preferem o uso da bandeja ou do prato para servir a refeição, houve a afirmação de que a preferência é pela bandeja "porque cabe mais" e "deixa as coisa separadinha...".

Durante o encontro, uma das participantes do grupo solicita, por meio de sua fala, a concordância da pesquisadora (que é nutricionista) no que diz respeito à relação entre alimento e força: "Eu acho que sim, né, que nem ali ele colocou na aula anterior, né, o Sérgio, né, que nem o precisa de comida assim, né, um pouco reforçada mais, né, que nem uns comem menos, outros comem mais, né, que nem o arroz e o feijão já sustentam, né, que são (?) quatro cinco horas que tu tem que passá ali e se tu não te alimenta bem durante o almoço, daqui uma ou duas horas tu já tá com fome de novo, né, e de- 
pende do que tu come durante o almoço já te sustenta e outras comidas talvez não tanto, né, aí..." (M. L.).

No trecho acima, há transgressão da máxima de modo quando da utilização da palavra aula para referir-se ao último encontro que tiveram e da solicitação do aval de uma figura masculina (Sérgio), ausente naquele momento, para ratificar o sentido de que só os alimentos fortes são comida.

\section{Desconhecimento/conhecimento do PAT}

Baseando-se nos repertórios analisados podese verificar que as trabalhadoras desconhecem a existência do programa governamental e suas diretrizes formalmente, mas sabem e dominam alguns fundamentos e, também, identificam a existência de um profissional responsável pelo refeitório, no caso, a nutricionista. Exemplo disto são os repertórios: "nutricionista", "valor nutricional", "ela que tem que calculá", "ela bota 10 (calorias), adquiri 5”, "calculou”, "ela fez a parte dela”, “acompanhou”.

O higienismo parece estar presente, não só na incorporação do discurso médico pelas trabalhadoras, mas também nos sentidos produzidos, por meio das práticas discursivas, para o lugar do nutricionista. Por um lado, os repertórios vinculam-se quase sempre ao cálculo, ao controle e à vigilância da atividade: "nenhuma nutricionista coloca tanta gordura", "as próprias cozinheiras não fazem certo”, "(as cozinheiras) não fazem como ela (nutricionista) ordena”, "vigiar mais a comida", "cardápio”, “aquilo que tá no cardápio da semana mantém”, "o refeitório tá inscrito (no PAT)”. A função, muitas vezes esperada do nutricionista na área de Alimentação Institucional, é exatamente a de controlar e vigiar, dentro de uma lógica que poderíamos denominar "higienista-taylorista" e, por outro lado, o trabalhador identifica a alimentação e o ato de alimentar-se na empresa também por meio de critérios de limpeza, higiene e linhas de produção.

Os diálogos remetem comumente às questões de controle, confidencialidade e confiança: “Às vezes eu pergunto pra mim, pô, mas se tem acompanhamento de nutricionista como é que tem isso aí ou então as próprias cozinheiras não, não, fazem certo como se diz, então, né. Não fazem como ela ordena, né, ou eles então tinham que vigiar mais a comida se realmente é assim como tá no cardápio".

"Ah, eu acho que tem, se tem uma nutricionista, então deve tê (controle), né, porque eu acho que é, cabe a ela, né, fazê o valor nutricional" (M. L.).
“Alimentação né, cada alimento tem (valor nutricional), né, ela que tem que calculá. Só que pessoa, às vezes, não adquiri (as calorias), né, às vezes, ela bota 10, né, e ela só adquiri 5, né, a gente deixa" (G.).

A análise das implicaturas conversacionais corrobora a análise dos repertórios lingüísticos descritos anteriormente. Nos trechos acima, pode-se argumentar que ocorre uma transgressão da máxima de pertinência, uma vez que não se esperava que a postura controladora do nutricionista, principalmente a posição de controle, estivesse tão claramente incorporada no discurso das trabalhadoras.

Pode-se, também, identificar que a questão do controle está relacionada com a qualidade da refeição. Diez-Garcia 33 demonstra em seu estudo que a comida de casa é identificada com adjetivos relacionados ao âmbito afetivo, e a comida industrial representa o distante e impessoal e tem uma conotação de ruim por haver desconhecimento e desconfiança em relação ao processo de preparo. Podemos identificar esta questão nos seguintes repertórios: "Tem que ser bem limpinho", "eu pego folhinha por folhinha, né, em casa”, "eles (do refeitório) não têm condições de fazê isso do jeito, né, que a gente tá acostumado", "tu encontra coisas", "bichinho", "plástico”.

De modo geral, os resultados do estudo demonstram que existe um desconhecimento formal sobre o PAT como política governamental, embora as trabalhadoras tenham revelado expressivos conhecimentos sobre a relação existente entre alimentação e saúde. O refeitório é reconhecido como um local onde o trabalhador "recarrega as baterias", ou seja, a alimentação na empresa tem a função de manter a força física, a capacidade para o desempenho das funções, de manter o corpo de pé, trabalhando. A disparidade que encontramos entre o perfil nutricional e o discurso relativamente sofisticado sobre o tema, pode indicar que a presença de obesidade ou sobrepeso, desde que não incapacitantes para o trabalho, não são tidos como prejudiciais. Ao contrário, neste caso, comer em excesso alimentos fortes parece estar relacionado diretamente à preservação da capacidade laboral e às necessidades de um processo de trabalho estranhado 34 e extremamente desgastante. Além disso, vale comentar, a posição do profissional nutricionista, claramente associada ao acompanhamento, controle e cálculo da refeição e não como agente promotor da saúde 12, posição esta desvinculada das atividades educativas e de orientação nutricional, atribuição definida no próprio programa e que parece, não vem sendo desenvolvida adequadamente nos locais de trabalho. 


\section{Considerações finais}

Entendemos que processos educativos em alimentação e nutrição devem ser estimulados no ambiente de trabalho. Campanhas que privilegiam somente a divulgação e difusão de orientações por meio de guias passo-a-passo não garantem adesão da população a práticas mais saudáveis que reflitam na qualidade de vida e podem até mesmo dificultar por não atingir os diferentes segmentos da sociedade que possuem "características, motivações e possíveis causalidades diferentes para a obesidade" 35 (p. 707).

Também Fonseca et al. 36, ao estudarem os hábitos alimentares entre funcionários de um banco estatal reforçam que enfocar, exclusivamente, o beneficio à saúde de mudanças na dieta não é suficiente para alterar os comportamentos alimentares, pois seus efeitos ocorrem em longo prazo e o prazer associado ao ato de comer é imediato. Savio et al. 12, avaliando o almoço servido a participantes do PAT, reforçam que ações voltadas para melhorar as opções alimentares dos trabalhadores devam incorporar uma visão mais holística, considerando as informações técnicas apenas como base para dar conta da situação nutricional corrente em nosso país.

Sobre a adequação das diretrizes nutricionais do PAT, não se pode deixar de ressaltar que, apesar do bom conhecimento dos trabalhadores sobre alimentação e sua relação com a saúde, o desenvolvimento do programa não consegue efetivamente repercutir na mudança do comportamento alimentar a ponto de contribuir na melhoria da qualidade de vida dos trabalhadores. Ações voltadas para a promoção da saúde desse grupo específico devem consi- derar não somente questões biológicas, mas também as que envolvam o contexto sócio-econômico e cultural no qual o trabalhador está inserido. Neste caso, o processo de trabalho mostrou-se fundamental no entendimento das relações entre alimentação/nutrição e o processo saúde-doença.

A Política Nacional de Alimentação e Nutrição (PNAN) do Ministério da Saúde determina diretrizes para a adequação de programas, projetos, planos e atividades relacionados à alimentação e nutrição, tornando-se parte integrante da Política Nacional de Saúde e inserindo-se no contexto da Segurança Alimentar e Nutricional 37. A PNAN tem como propósito a garantia da qualidade dos alimentos colocados para consumo no país, a promoção de práticas alimentares saudáveis e a prevenção e o controle dos distúrbios nutricionais, bem como o estímulo às ações intersetoriais que propiciem o acesso universal aos alimentos 37 .

Frente a isto, devemos considerar que o PAT, sob responsabilidade do MTE, pode vir a se constituir num dos principais instrumentos para a efetivação das diretrizes propostas. Deve-se considerar que as estratégias, tanto traduzidas em recomendações nutricionais, como em ações de educação nutricional, devam ser rediscutidas no âmbito do próprio Programa e, conseqüentemente, das práticas em UAN.

Para tanto acredita-se que uma reflexão mais aprofundada deva permear o debate sobre alimentação, saúde, trabalho e políticas públicas, tendo em vista a descentralização e regionalização das ações, respeitando-se as realidades de cada local e abarcando não somente questões pontuais, mas permitindo uma discussão ampliada numa perspectiva intersetorial, interdisciplinar e multiprofissional.

\section{Resumo}

Este estudo objetivou analisar as concepções dos trabalhadores em relação ao Programa de Alimentação do Trabalhador numa indústria coureiro-calçadista da região do Vale dos Sinos, Rio Grande do Sul, Brasil, por meio da análise das práticas discursivas de trabalhadores e da caracterização do perfil epidemiológico. Um estudo descritivo foi realizado a partir do levantamento de dados demográficos, socioeconômicos e antropométricos. A abordagem qualitativa dos temas alimentação/nutrição, saúde, política pública foi feita a partir da realização de grupo focal utilizando-se o referencial de análise de práticas discursivas e produção de sentidos. Argumenta-se que existe um bom conhecimento, por parte dos trabalhadores, das relações entre saúde e alimentação. Entretanto, o programa em si é ignorado e não tem conseguido atingir seu objetivo de promover a saúde. Sugere-se que novas práticas educativas devam ser implementadas pelo setor de nutrição nos locais de trabalho. No âmbito das políticas públicas referentes à Nutrição, uma reflexão mais aprofundada deve permear o debate tendo em vista a descentralização e regionalização das ações referentes à saúde do trabalhador e abarcando não somente questões pontuais, mas permitindo a discussão ampliada numa perspectiva intersetorial, interdisciplinar e multiprofissional.

Programas e Políticas de Nutrição e Alimentação; Saúde Ocupacional; Alimentação 


\section{Colaboradores}

D. Stolte, E. A. Hennington e J. S. Bernardes trabalharam em conjunto na concepção teórica, elaboração e redação final do texto. $\mathrm{O}$ trabalho de campo foi organizado, coordenado e executado por D. Stolte.

\section{Referências}

1. Prata PR. A transição epidemiológica no Brasil. Cad de Saúde Pública 1992; 8:168-75.

2. Patarra NL. Mudanças na dinâmica demográfica. In: Monteiro CA, organizador. Velhos e novos males da saúde no Brasil. São Paulo: Editora Hucitec/Núcleo de Pesquisas Epidemiológicas em Nutrição e Saúde, Universidade de São Paulo; 2000. p. 61-78.

3. Monteiro CA, Mondini L, Sousa ALM, Popkin BM. Da desnutrição para a obesidade: a transição nutricional no Brasil. In: Monteiro CA, organizador. Velhos e novos males da saúde no Brasil. São Paulo: Editora Hucitec/Núcleo de Pesquisas Epidemiológicas em Nutrição e Saúde, Universidade de São Paulo; 2000. p. 247-55.

4. Escoda MSQ. Para a crítica da transição nutricional. Ciênc Saúde Coletiva 2002; 7 :219-26.

5. Nascimento LC, Mendes IJM. Perfil de saúde dos trabalhadores de um Centro de Saúde-Escola. Rev Latinoam Enfermagem 2002; 10 Suppl 4:502-8.

6. Proença RPC. Inovação tecnológica na produção de alimentação coletiva. Florianópolis: Editora Insular; 1997.

7. Ministério do Trabalho e Emprego. Programa de Alimentação do Trabalhador: legislação. 6a Ed. Brasília: Departamento de Segurança e Saúde no Trabalho, Secretaria de Inspeção do Trabalho, Ministério do Trabalho e Emprego; 2002.

8. Ministério do Trabalho e Emprego. Orientação da educação alimentar. http://www.mte.gov.br/Te mas/PAT.asp (acessado em 04/Abr/2005).

9. Ministério do Trabalho e Emprego. Programa de Alimentação do Trabalhador: Portaria no 116. Brasília: Departamento de Segurança e Saúde no Trabalho, Secretaria de Inspeção do Trabalho, Ministério do Trabalho e Emprego 2005.

10. Burlandy L, Anjos LA. Acesso a vale-refeição e estado nutricional de adultos beneficiários do Programa de Alimentação do Trabalhador no Nordeste e Sudeste do Brasil 1997. Cad Saúde Pública 2001; 17:1457-64

11. Veloso IS, Santana VS. Impacto nutricional do programa de alimentação do trabalhador no Brasil. Rev Panam Salud Pública 2002; 11:24-31.
12. Savio KEO, Costa THM, Miazaki E, Schmitz BAS. Avaliação do almoço servido a participantes do programa de alimentação do trabalhador. Rev Saúde Pública 2005; 39:148-55.

13. Castro MBT, Anjos LA, Lourenço PM. Padrão dietético e estado nutricional de operários de uma empresa metalúrgica do Rio de Janeiro, Brasil. Cad Saúde Pública 2004; 20:926-34.

14. World Health Organization. Dieta, nutrición y prevención de enfermedades crónicas: informe de una consulta mixta de expertos. Geneva: World Health Organization/Food and Agriculture Organization; 2003. (Serie de Informes Técnicos, 916).

15. Han TS, van Leer EM, Seidell JC, Lean ME. Waist circumference action levels in the identification of cardiovascular risck factors: prevalence study in a random sample. BMJ 1995; 311:1401-5.

16. Spink MJ, Lima H. Rigor e visibilidade: a explicitação dos passos da interpretação. In: Spink MJ, organizadora. Práticas discursivas e produção de sentidos no cotidiano: aproximações teóricas e metodológicas. São Paulo: Cortez Editora; 2000. p. 93-122.

17. Spink MJ. Linguagem e produção de sentidos no cotidiano. Porto Alegre: EDIPUCRS; 2004.

18. Grice HP. Presuposición e implicatura conversacional. In: Julio MT, Muñoz R, compiladores. Textos clásicos de pragmática. Madrid: Arco Libros; 1970. p. 105-24.

19. Olinto MTA, Nacul LC, Gigante DP, Costa JSD, Menezes AMB, Macedo S. Waist circumference as a determinant of hipertension and diabetes in Brazilian women: a population-based study. Public Health Nutr 2004; 7 Suppl 5:629-35.

20. Canesqui AM. Antropologia e alimentação. Rev Saúde Pública 1988; 22:207-16.

21. Woortmann K. O sentido simbólico das práticas alimentares. In: 1o Congresso de Gastronomia e Segurança Alimentar. Brasília: Universidade de Brasília; 2004.

22. Helmann CG. Cultura, saúde \& doença. Porto Alegre: Artmed; 2003.

23. Poulain JP. Sociologias da alimentação: os comedores e o espaço social alimentar. Florianópolis: EdUFSC; 2004. 
24. Lima M J. O que é enfermagem. São Paulo: Editora Brasiliense; 1993.

25. Bosi MLM. Profissionalização e conhecimento a nutrição em questão. São Paulo: Editora Hucitec; 1996.

26. Vasconcelos FAG. O nutricionista no Brasil: uma análise histórica. Rev Nutr 2002; 15:127-38.

27. Viana SV. Nutrição, trabalho \& sociedade. São Paulo: Editora Hucitec/Salvador: Editora da UFBA; 1996.

28. 31 de agosto - Dia do Nutricionista. Uma categoria em plena transformação. Nutrinews 1999. http:// www.nutrinews.com.br/edicoes/9909/mat02.html (acessado em 31/Mai/2005).

29. Bleil SI. O padrão alimentar ocidental: considerações sobre a mudança de hábitos no Brasil. Cadernos de Debates 1998; VI:1-25.

30. Garcia RWD. Reflexos da globalização na cultura alimentar: considerações sobre as mudanças na alimentação urbana. Rev Nutr 2003; 16:483-92.

31. Garcia RWD. A comida, a dieta, o gosto: mudanças na cultura alimentar [Tese de Doutorado]. São Paulo: Departamento de Psicologia Social e do Trabalho, Instituto de Psicologia, Universidade de São Paulo; 1999.
32. Mintz SW. Comida e antropologia: uma breve revisão. Rev Bras Cienc Soc 2001; 16:31-42.

33. Diez-Garcia RW. Práticas e comportamento alimentar no meio urbano: um estudo no centro da Cidade de São Paulo. Cad Saúde Pública 1997; 13:455-67.

34. Antunes, R. Adeus ao trabalho? Ensaios sobre as metamorfoses e a centralidade do mundo do trabalho. São Paulo: Cortez Editora/Campinas: Editora da Unicamp; 2003.

35. Mendonça CP, Anjos LA. Aspectos das práticas alimentares e da atividade física como determinantes do crescimento do sobrepeso/obesidade no Brasil. Cad Saúde Pública 2004; 20:698-709.

36. Fonseca MJM, Chor D, Valente JG. Hábitos alimentares entre funcionários de banco estatal: padrão de consumo alimentar. Cad Saúde Pública 1999; 15:29-40.

37. Ministério da Saúde. Política Nacional de Alimentação e Nutrição. Brasília: Departamento de Atenção Básica, Secretaria de Atenção à Saúde, Ministério da Saúde; 2003.

Recebido em 09/Ago/2005

Versão final reapresentada em 03/Nov/2005 Aprovado em 19/Dez/2005 